\title{
Prueba, verdad y justicia de transición. El caso de Cecilia Magni y Raúl Pellegrin (Corte Suprema)
}

\author{
Comentario de Daniela Accatino Scagliotti*
}

Santiago, cuatro de agosto de dos mil catorce.

VISTOS:

En estos autos Rol N ${ }^{\circ}$ 5004-1988, del Segundo Juzgado del Crimen de San Fernando, por sentencia de dieciocho de octubre de 2010, pronunciada por el Ministro en Visita Extraordinaria don Raúl Eduardo Mera Muñoz, escrita de fojas 3.018 a 3.061, se absolvió a los acusados Julio Verne Acosta Chávez, Carlos Mauricio Bezmalinovic Hidalgo, Juan Ernesto Rivera Iratchet y Walther Soto Medina de la acusación que se les fomulara de ser coautores de los delitos de homicidio calificado cometidos en las personas de Raúl Pellegrin Friedmann y Cecilia Magni Camino, supuestamente cometidos en la jurisdicción de San Fernando en día indeterminado de octubre de 1988. Enseguida se acogió la excepción de incompetencia absoluta del tribunal para conocer de la acción civil dirigida en contra del Fisco de Chile, omitiéndose pronunciamiento respecto de esa demanda y, por último, se rechazó la acción indemnizatoria deducida por los querellantes Rafael Walker Salgado y Carla Pellegrin Friedmann en contra de los acusados, sin costas, por haber tenido motivo plausible para intentarla.

Esa decisión fue impugnada por la vía de los recursos de casación en la forma y apelación, y la Corte de Apelaciones de Rancagua, por sentencia de veintidós de julio de dos mil trece, a fojas 3.308, desestimó los arbitrios de casación confirmando el fallo de primer grado.

Contra el anterior pronunciamiento doña Carla Pellegrin Friedmann y don Rafael Walker Salgado, partes querellantes en la causa, asistidos por la abogada señora Ema Salinas Fernández, dedujeron recurso de casación en el fondo; en tanto que doña Lya Hald Ramírez, Abogado Procurador Fiscal de Rancagua del Consejo de Defensa del Estado, por el Fisco de Chile, formalizó recursos de casación en la forma y en el fondo contra el mismo dictamen.

* Licenciada en Ciencias Jurídicas y Sociales, Universidad de Chile; Doctora en Derecho, Universidad de Granada; Profesora de Razonamiento Jurídico y Derecho Probatorio de la Universidad Austral de Chile. Correo electrónico: daccatino@uach.cl. Este trabajo ha sido desarrollado en el marco del Proyecto Fondecyt No 1151528 "Prueba judicial y justicia de transición”, del que la autora es investigadora responsable. 
Declarados admisibles los indicados recursos, a fojas 3.468 se ordenó traer los autos en relación.

CONSIDERANDO ${ }^{1}$ :

PRIMERO: Que el recurso de casación en el fondo promovido por la parte querellante a fojas 3.339 de estos antecedentes se funda en las causales cuarta y séptima del artículo 546 del Código de Procedimiento Penal.

En relación a la denuncia de infracción a las leyes reguladoras de la prueba se sostiene que la sentencia no respetó los artículos 459, 472, 476, 478, 481, 485 y $488 \mathrm{~N}^{\text {os }} 1^{\circ}, 2^{\circ}$ y $4^{\circ}$ del Código de Procedimiento Penal, lo que provocó un error en la determinación de los hechos que, consecuencialmente, fueron calificados como lícitos, lo que genera el quebrantamiento de las disposiciones sustantivas contenidas en los artículos $1^{\circ}, 14$ $\mathrm{N}^{\circ} 1,15 \mathrm{~N}^{\circ} 1,50,68,69,74$ y $391 \mathrm{~N}^{\circ} 1$ del Código Penal.

Plantea el recurso que de conformidad con lo que prescribe el artículo 485 del Código de Procedimiento Penal son hechos que han debido presumirse, la aprehensión o detención ilegal de Raúl Pellegrin y Cecilia Magni y su muerte por acción de terceros. En relación al primero de estos hechos, asegura que se acreditó que un grupo importante de policías buscaba a las víctimas en un sector cercano al que se hallaban, quienes para traspasar el cerco policial sólo podían enfrentarlo. Fueron encontrados muertos a cuatro kilómetros del lugar de la detención, río arriba, lo que descarta la tesis del fallo del arrastre por las aguas. Tales acontecimientos surgen de las declaraciones de los integrantes del Frente Patriótico Manuel Rodríguez y de los funcionarios de las fuerzas policiales desplegadas en el sector, del informe del Prefecto de Colchagua Walter Soto Medina de fojas 921, del acta de inspección personal del tribunal en Hueñi, de fojas 1050, de las declaraciones de los cuidadores de la comunidad Hueñi de fojas 1127 y 1128, de Juan Rivera Iratchet de fojas 441 y de Sergio Lutjens, a fojas 994, en particular acerca del número de efectivos que se desplegaron para la búsqueda.

La detención que así ha podido declararse fue ilegal porque no existía orden para ese efecto, no se encontraban en hipótesis de flagrancia, no fueron puestos a disposición de la Comisaría de San Fernando, encontrándose sus cuerpos dos días después de la aprehensión en el cauce del río.

En relación a su muerte por intervención de terceros se sostiene que las pericias descartaban la asfixia por inmersión y que el origen de las lesiones fuese provocado por arrastre, por lo que al concluir lo contrario se desatendió el artículo 472 del Código de Procedimiento Penal, sobre el valor probatorio que la ley asigna al peritaje.

En cuanto a los responsables de tales sucesos asegura que la prueba reunida incrimina a los acusados Rivera Iratchet, Comisario de la Comisaría de San Fernando, quien participó en el operativo de búsqueda de las víctimas que testigos sitúan en Hueñi el 27

\footnotetext{
${ }^{1}$ Se reproducen sólo los considerandos referidos a la determinación de los hechos que resuelven el recurso de casación en el fondo. La sentencia completa puede verse en http://www.pjud.cl/documents/396729/0/ MAGNI+Y+PELLEGRIN+SUPREMA.pdf/c508aa81-bb37-4783-bbd6-c846bc0f97e3.
} 
de octubre de 1988, a las 14:00 horas, y que escaparon sólo minutos antes de la llegada de la patrulla comandada por Rivera, por un sector del cual era muy difícil escapar; Carlos Bezmalinovic, jefe de la patrulla del Gope que llegó a la comunidad Hueñi pocas horas después de que Rivera la había allanado; Walter Soto Medina, Prefecto de Colchagua, quien dirigió la operación con personal de su dependencia, entre ellos Rivera Iratchet, a cargo del mando y control operativo de la misión de detección, neutralización y captura del grupo terrorista que atentó contra el poblado y Retén Los Queñes y de todas las operaciones que formaban parte del Plan Lince, tendientes al rastreo y captura de Raúl Pellegrin y Cecilia Magni; Julio Verne Acosta Chávez, Subprefecto de los Servicios, a quien correspondió tomar el mando de las operaciones a contar del tercer día del asalto.

En síntesis, se sostiene que de la prueba producida en el juicio fluye con nitidez que ambas víctimas fueron detenidas el 27 de octubre de 1988 por los carabineros que conformaban un cerco policial en la zona y, estando en poder de sus captores, les fueron infligidas determinadas lesiones descritas como torturas por las convenciones internacionales, hasta provocarles la muerte, para luego abandonar sus cuerpos en el cauce del río Tinguiririca a fin de simular que la causa de sus decesos fue asfixia por sumersión. En tales hechos los acusados intervinieron en calidad de autores, en conformidad con lo que prescribe el artículo $15 \mathrm{~N}^{\circ} 3$ del Código Penal.

Con esos argumentos se solicita la invalidación de la sentencia impugnada a fin que en su reemplazo se dicte otra que condene a los acusados como autores de los delitos de homicidio calificado de Raúl Pellegrin y Cecilia Magni y que, por ello, se acoja en todas sus partes la demanda civil presentada por su parte.

Segundo: Que enseguida, en lo principal de fojas 3.373, la Abogada Procurador Fiscal de Rancagua, por el Fisco de Chile, dedujo recurso de casación en la forma por la causal del artículo $541 \mathrm{~N}^{\mathrm{o}} 9$ del Código de Procedimiento Penal, en relación al artículo 500 $\mathrm{N}^{\text {os }} 3$ y 4 del mismo cuerpo legal.

Postula el recurso que el fallo omitió hacer una exposición de los hechos y las consiguientes pruebas que dieron origen a los autos de procesamiento y a las acusaciones, porque no se especifican qué hechos precisos se atribuyen a los procesados ni todos los elementos que fundaron los cargos, como ocurre, por ejemplo, con las declaraciones de los propios acusados y de los testigos Félix Ugalde de fojas 33 y 1127 , concordante con la del testigo presencial Claudio Araya Fuentes; de Lorenzo Zamorano de fojas 190, y de Lorenzo González Cabezas, de fojas 550, además de las pericias cuyo mérito es valorado negativamente, obviándose, por último, toda referencia y valoración al acta de inspección del tribunal, lo que hace que la sentencia no se baste a sí misma.

Como consecuencia de estas deficiencias solicita se declare la nulidad del fallo y se dicte la correspondiente sentencia de reemplazo que sin incurrir en omisiones acerca de la prueba allegada al proceso, condene a los acusados como autores de los dos delitos de homicidio pesquisados.

Tercero: Que la misma defensa fiscal, en el primer otrosí de fojas 3.373, formalizó recurso de casación en el fondo por las causales cuarta y séptima del artículo 546 del 
Código de Procedimiento Penal, denunciándose la infracción de los artículos 459, 472 , 474, 476, 478 y $488 \mathrm{~N}^{\text {os }} 1,2$ y 4 del Código de Procedimiento Penal y los artículos 1 , $14 \mathrm{~N}^{\circ} 1,15 \mathrm{~N}^{\mathrm{o}} 1,50,68,69,74$ y $391 \mathrm{~N}^{\circ} 1$ del Código Penal.

Se sostiene por el recurso que, a diferencia de lo que razona el fallo, no existe contradicción sustancial entre los peritajes médicos, no acatándose por todos ellos los requisitos de los artículos 472 y 473 del Código de Procedimiento Penal, incurriéndose en error de derecho al valorarlos como si se tratase de informes equivalentes. Adicionalmente se expresa que existe innumerable prueba de presunciones que se orienta hacia una única conclusión, cual es que las víctimas fueron capturadas por carabineros en su huida desde la comunidad Hueñi el 27 de octubre de 1988 y que fueron torturadas y golpeadas y lanzadas al río, muertos o agonizantes.

En relación a la infracción denunciada al artículo 488 N $^{\text {os }} 1$ y 2 del Código de Procedimiento Penal, argumenta que existen hechos reales y probados que no fueron valorados como base para el establecimiento de presunciones judiciales. Es así como ha debido declararse que como consecuencia del asalto al poblado de Los Queñes y la muerte de un carabinero en ese lugar, el alto mando de la institución, a partir del 21 de octubre de 1988, organizó en la zona comprendida entre Curicó y San Fernando un vasto operativo policial con el fin de detener a los responsables, para lo cual se ordenó el desplazamiento de un gran contingente de funcionarios del GOPE, de la Sección IV de Inteligencia o DAICAR, patrulla de acciones especiales y funcionarios policiales de la propia Prefectura de Colchagua y del Retén Puente Negro, a lo que se sumó el envío de vehículos terrestres, tres helicópteros y perros adiestrados, medios materiales que quedaron al mando del Prefecto de Colchagua Walter Soto Medina, siendo el Subprefecto de los Servicios el teniente coronel Julio Acosta Chávez.

Asimismo, debió darse por probado que el 27 de octubre de 1988 Cecilia Magni y Raúl Pellegrin se encontraban en la comunidad Hueñi, en el sector La Rufina, a 30 kilómetros de San Fernando, escapando media hora antes de que arribara el contingente policial que andaba tras su búsqueda. Sin embargo el fallo descarta que las víctimas huyeran poco antes de la llegada de Carabineros dadas las aparentes contradicciones entre los dichos de los frentistas Araya y Órdenes, lo que restaría valor a sus declaraciones, y el relato de la cuidadora del lugar, quien dijo que los fugitivos habrían partido dos horas antes de la llegada de los policías, en circunstancias que no estaba presente al momento de la partida de las víctimas. Sobre este punto el fallo desestima sin razón la versión de dos testigos hábiles, presenciales y contestes -Claudio Araya y Félix Ugalde-, de manera que al restar mérito a sus dichos se contraviene el artículo 459 del Código de Procedimiento Penal. También se argumenta que los informes médico legales fijan como data probable de la muerte el 29 de octubre de 1988, de modo que si huyeron dos días antes, el día 27 , no es plausible sostener que permanecieron dos días sin ser vistos y que los funcionarios no encontraran sus cuerpos en ese tiempo. El fallo descarta la existencia de detención y tortura porque no se escucharon gritos, en circunstancias que ambos pudieron encontrarse maniatados.

Luego refiere que son hechos acreditados que las víctimas huyeron al suroriente, hacia la cordillera, en sentido contrario al río, pues para alcanzar sus aguas habrían 
tenido que retornar por la ruta por la que se acercaban las fuerzas policiales, de modo que solo es posible aceptar la tesis de que los cuerpos fueron trasladados al lugar de su hallazgo. Las vestimentas de las víctimas no presentaban rasgaduras compatibles con las lesiones de los cuerpos, lo que parece incompatible con la tesis de que murieran ahogadas al tratar de cruzar el río, sino más bien revela que fueron objeto de torturas y posteriormente asesinadas.

Por último refiere que como consecuencia del rechazo de la existencia de los delitos, se negó, también con error de derecho, la responsabilidad penal de los acusados, dejándose de valorar las pruebas de cargo que fluían en su contra, pretiriendo la aplicación de las normas que castigan la participación criminal. Es así como debió dejarse sentado que Rivera Iratchet atrapó a las dos víctimas y no los puso a disposición de la Comisaría a su mando, sino que los entregó al teniente Bezmalinovic, Jefe de la patrulla del Gope que llegó a la comunidad Hueñi el 27 de octubre. Al momento que la Prefectura de Colchagua, cuyo prefecto era el acusado Walter Soto Medina, tomó conocimiento del atentado, dispuso de apoyo y medios logísticos a la unidad atacada y controla, coordina y evalúa el operativo policial, puesto en ejecución por la Primera Comisaría de San Fernando, y comisiona como coordinador en terreno de las unidades al Subprefecto de los Servicios de la Prefectura de Colchagua teniente coronel Julio Verne Acosta.

Finaliza solicitando que se anule el fallo de alzada y se dicte la correspondiente sentencia de reemplazo que condene a los acusados como autores de dos delitos de homicidio calificado y, por tanto, se acoja la demanda civil deducida por su parte (sic).

En cuanto al recurso de casación en la forma deducido por el Fisco de Chile:

$(\ldots)$

EN CUANTO A LOS RECURSOS DE CASACIÓN EN EL FONDO:

SÉPtimo: Que los recursos de casación en el fondo promovidos por la parte querellante y por el Consejo de Defensa del Estado se sustentan en unas mismas causales y denuncian, en lo fundamental, los mismos errores de derecho, por lo que se procederá a su estudio y decisión conjunta.

Octavo: Que según consta de fojas 2754, los hechos por los cuales se formuló acusación contra los enjuiciados consistieron en que dentro de los últimos días del mes de octubre de 1988, en el marco de los operativos practicados por carabineros luego del asalto a la localidad de Los Queñes por una fracción del Frente Patriótico Manuel Rodríguez, fueron capturados dos de los cabecillas de ese grupo mientras huían del sector, Raúl Pellegrin y Cecilia Magni, a quienes se dio muerte golpeándolos ruda y repetidamente en zonas vitales, no sin antes atormentarlos inhumanamente con el solo propósito de aumentar su dolor, todo ello por parte de funcionarios de carabineros encargados de su custodia, mientras las víctimas se encontraban reducidas y completamente indefensas. La muerte de ambos ofendidos se produjo como precisa consecuencia de las lesiones que les provocaron los golpes recibidos por parte de sus 
captores y custodios, sin perjuicio de que éstos arrojaron sus cuerpos agonizantes al río Tinguiririca, tanto con la intención de completar el propósito homicida como para simular de este modo una muerte por inmersión de carácter accidental.

Noveno: Que el fallo que se revisa sostiene que los antecedentes probatorios no son suficientes para dar por establecida la existencia de los delitos de homicidio, porque no basta que la muerte sea sospechosa o que algunos elementos de la causa apunten a la conclusión de que ésta pudo ser provocada, sino que se requiere de un grado de certeza mayor, lo que implica que la prueba sea seria y convincente y que no haya contradicciones insalvables.

Sobre este tópico apunta la sentencia que todo el caso descansa en los peritajes, porque no hay prueba directa de los hechos, y esas conclusiones deben valorarse de conformidad a lo que dispone el artículo 473 del Código de Procedimiento Penal, siendo los informes de autopsia los únicos que se practicaron analizando los cadáveres, los demás son peritajes sobre peritajes.

En torno a esta prueba declaró la sentencia que del solo examen de las autopsias no cabe dar por cierto que las muertes constituyan homicidios. La de Pellegrin, indica como causa de muerte asfixia por sumersión y contusiones dorsales, informe que es contradictorio con el de la Universidad de Chile que no considera como causa de la muerte la asfixia y tampoco el traumatismo dorsal, sino que apunta que ésta tuvo su origen en el traumatismo cráneo encefálico. La ampliación de la autopsia califica ese traumatismo como grave y mortal, no obstante que en sus conclusiones no se considera como causa de muerte tales lesiones, a pesar que ellos mismos las califican de mortales, y por otro lado, incluyen como causas del deceso lesiones torácicas dorsales, a las que los médicos de la Universidad de Chile no asignan esa calidad. También la autopsia describe lesiones en la zona anal sin hacer ninguna referencia a que puedan ser causadas por terceros y menos mediante la introducción forzada de objetos. En la ampliación del informe en cambio se dice que se trata de alteraciones más propias de explicar por la acción de terceros, pero adicionalmente indica que el estudio histológico constató la presencia de várices sin infiltración sanguínea, con lo que queda descartada la equimosis e infiltración y sólo resta la dilatación en el ano y lesiones muy menores que sólo comprometen la epidermis y no el canal rectal.

Por otra parte, el fallo asienta que la autopsia de Cecilia Magni contempla como causa de muerte exclusivamente asfixia por sumersión en el agua y otras lesiones que concluye son explicables por el arrastre de las aguas u otras causas que no especifica. También describe lesiones menores y superficiales en la zona anal y la presencia de infiltraciones sin hacer mención a una posible atribución a terceros. En la ampliación a ese informe se señala que el estudio histológico demostró que se trataba de cuerpos venosos dilatados, es decir no apunta a la posible introducción de objetos. Pero ese informe es contradictorio con el de la Universidad de Chile, que asienta la tesis sobre las que se construyen las acusaciones, el que descarta la asfixia como causa de la muerte y supone en cambio como tal un trauma raquimedular y atribuye a las lesiones de la zona anal el carácter de lesiones causadas por introducción forzada de objeto romo. 
Es decir, con esos datos consignados en los informes de autopsia el fallo declara que no es posible afirmar que las dos muertes constituyan homicidios ni que las heridas tengan su origen en la acción de terceros, dudas que no se disiparían con las declaraciones de los peritos médicos que las practicaron, incorporando el texto de la sentencia una referencia a los dichos de estos facultativos.

Luego de insistir en elucubraciones técnicas en torno a estas probanzas, asilado en las conclusiones del informe del doctor José Belletti Barrera, de fojas 3007, quien afirma que tanto las características externas de los cuerpos como los hallazgos internos orientan a estimar que la causa de las muertes fue asfixia por sumersión en el agua, el fallo razona que efectivamente las autopsias describen signos inequívocos de asfixia, por lo que la existencia de traumas, dadas las diversas versiones y posibles causas que los explican, conducen al tribunal a desestimar ese hallazgo, por carecer de elementos para preferir una tesis sobre otra, dando por cierto que, finalmente, la prueba apunta a una caída accidental al río de ambos prófugos.

Décimo: Que dadas las conclusiones y hallazgos que arrojan todas las pericias verificadas en la causa, es posible sostener que Cecilia Magni Camino y Raúl Pellegrin Friedmann murieron a consecuencia de las torturas y maltratos provocados por terceros.

En efecto, el informe del Departamento de Medicina Legal de la Facultad de Medicina de la Universidad de Chile concluye que ambas víctimas murieron como consecuencia de traumatismos de tipo raquimedular, la primera, y cráneo encefálico, el segundo, conclusión que aparece corroborada con aquella a que arribaron el Director del Servicio Médico Legal y el Jefe del Departamento de Tanatología de ese mismo Servicio, según ampliación de los informes de autopsia de fojas 287 y siguientes.

Estos documentos dan cuenta de manera cierta que las lesiones encontradas en los cuerpos de las víctimas no fueron consecuencia del arrastre de las aguas, teoría a la que adhiere el fallo, sino que corresponden al resultado de la acción de terceros, y que por su naturaleza tampoco pudieron ser autoinferidas.

UndÉcImo: Que es un hecho objetivo que ambas víctimas presentan un claro patrón de lesiones similar, lo que da cuenta que las lesiones las habrían provocado las mismas personas y en tiempos relativamente cercanos, sino en forma simultánea, pues es coincidente la oportunidad en que fueron vistos con vida por última vez y el hallazgo de sus cuerpos sólo difiere en un escaso lapso de tiempo.

En este sentido, los informes periciales son coincidentes en afirmar que las lesiones de las víctimas fueron provocadas mientras permanecían desnudas, lo que guarda armonía y coherencia con el buen estado de sus ropas y aleja la falta de concordancia entre las lesiones con la infiltración sanguínea y la carencia de rastros en las vestimentas. Lo propio sucede con las lesiones ano rectales encontradas en ambos cuerpos, las que sólo pudieron ser provocadas mientras permanecían desnudos. Incluso el estudio histológico realizado por el Servicio Médico Legal a las muestras de tejidos correspondientes al cadáver de Cecilia Magni, da cuenta que "aunque la erosión de la piel anal no es característica, la erosión ampollar de la vecindad es altamente sugerente de haber sido producida por calor 
como se describe en la periferia de lesiones por electricidad de bajo voltaje”. El mismo informe añade que las lesiones de la médula espinal y de las pieles mastoideas son muy cercanas a la muerte, lo que no sucede en el caso de las lesiones anales, que resultaron ser previas, más de veinticuatro horas.

Duodécimo: Que las conclusiones que consigna el fallo acerca de la aparente contradicción de los informes en torno a la causa de muerte, dada la existencia conjunta de lesiones y traumas que se califican de mortales y los signos asfícticos que revelan los cuerpos, lo que pudo suceder en fase terminal, no es tal, pues la misma prueba, que en esta parte se ha obviado, permite concluir que en el deceso pueden confluir múltiples causas, todas contribuyentes al resultado mortal. No es atendible la conclusión del fallo en cuanto a que un traumatismo raquimedular, como el que presentó Cecilia Magni, por ejemplo, descarte la posibilidad de la muerte por el hecho que numerosas personas viven con paraplejia. Lo que apunta el informe de la Universidad de Chile es que una lesión de esa entidad, unida a la sumersión en el agua, es mortal, porque la víctima no está en condiciones físicas de poder sobrevivir si no es auxiliada por terceros.

Décimo Tercero: Que lo mismo se advierte en el caso de Raúl Pellegrin. El traumatismo cráneo encefálico, por sí solo, puede no ocasionar la muerte, que es lo que se advierte de la autopsia, pero quien lo padece, tras la inmersión en el agua, fallecerá por asfixia, dadas las nulas posibilidades de sobrevivir con una lesión de esa naturaleza. No hay contradicción en torno a las causas de la muerte, porque se trata de factores contribuyentes al mismo resultado.

Décimo Cuarto: Que, por otra parte, como constató el tribunal en la diligencia de fojas 1050, tras la estadía de los prófugos en el poblado de Hueñi, estos emprendieron la huida por una huella que se interna hacia el sureste, de manera que para alcanzar el río Tinguiririca, donde se encontraron sus cuerpos sin vida, habrían tenido que devolverse tomando la ruta por la que se acercaban las fuerzas especiales, según ellos mismos advirtieron vía radial, de manera que ese camino no era útil a sus fines. En la indicada huella de escape se encontraron armas y efectos personales de los ofendidos, lo que demuestra que esa fue la senda por el que optaron, la que se aleja del río, quedando sin explicación, más que por la intervención de terceros, que sus cuerpos sin vida, golpeados, hayan sido avistados por un lugareño en el lecho del río.

DÉcimo Quinto: Que esta multiplicidad de hechos, reales y probados, permiten establecer presunciones de tal entidad que llevan inequívocamente a concluir que ambas víctimas, perseguidas por las fuerzas policiales en las cercanías del río donde fueron encontrados sus cuerpos, fueron detenidas, golpeadas y arrojadas al cauce torrentoso moribundas, con lo que el desenlace conocido era inevitable.

Décimo Sexto: Que sin embargo, a pesar del hecho acreditado de la muerte por acción de terceros, no existe la misma contundencia probatoria para sostener que alguno de 
los acusados provocara la muerte de las víctimas, ya sea autónomamente o por orden superior. En efecto, se procesó a Rivera y a Bezmalinovic porque fueron los primeros en arribar al campamento Hueñi. Los enjuiciados Soto y Acosta fueron procesados por sus calidades de jefes superiores a cargo de la dirección del operativo.

Décimo Séptimo: Que la intervención de los dos primeros -Rivera y Bezmalinovicparte de la premisa que fueron detenidos en Huañi, de lo que no hay prueba directa ni indiciaria, lo que solo ha podido presumirse, pero en ese caso las acusaciones que se les formulan de ser autores de los homicidios, materiales o intelectuales, se sostendrían en presunciones fundadas en otras presunciones.

Si las autopsias fijan la muerte el día 29 de octubre, y las víctimas abandonaron el campamento el día 27, esa circunstancia solo acredita el hecho de la detención, momento en que les fueron infligidas las torturas, pero si como sostiene el fallo, no se escucharon gritos y ningún carabinero del numeroso contingente que se encontraba en el lugar advirtió nada, no es posible vincular a los acusados con ese hecho, que si se supone existió, se acordó un pacto de silencio para ocultarlo, lo que efectivamente, como declara el fallo es ir más allá de lo razonable y de la prueba de la causa.

Décimo Octavo: Que de acuerdo a lo que dispone el artículo 772 del Código de Procedimiento Civil, aplicable en la especie por la remisión que hace el artículo 535 del de Procedimiento Penal, es un presupuesto básico para el éxito del recurso no sólo que exista la inobservancia reclamada sino que, además, el recurrente sufra un perjuicio reparable solo con la invalidación del fallo o que el vicio reclamado influya sustancialmente en lo dispositivo del mismo, esto es que concurra un efecto trascendente y concreto que implique una variación concreta de lo resuelto que pueda ser verificada jurídicamente.

Como se desprende de las reflexiones precedentes, este Tribunal ha arribado a la convicción de que las víctimas Cecilia Magni Camino y Raúl Pellegrin Friedmann fueron muertas por la acción de terceros.

Pero para la emisión de un fallo condenatorio, no basta con adherirse a una teoría o hipótesis de cómo sucedieron los hechos. En este sentido, el planteamiento de las partes acusadoras e impugnantes del fallo se sostiene en un hecho que no pudo ser probado, cual es que las víctimas fueron detenidas por los acusados, como consecuencia de sus precisas instrucciones o por orden superior, y que ellos procedieron a golpearlos para luego ser arrojados al cauce del río Tinguiririca mientras agonizaban, con el objeto de causarles la muerte o hacer aparecer ésta como un accidente con motivo de la fuga.

En consecuencia, incluso conviniendo que en la especie están configurados los delitos de homicidio materia de las averiguaciones, no es posible imputar en ellos participación de autor, cómplice o encubridor a los acusados, de manera que la sentencia que puede emitirse como consecuencia de acoger los recursos de casación en el fondo dado el error constatado en el establecimiento de los hechos que causaron la muerte de las víctimas, resulta ser igual a la que se revisa. No existe, entonces, influencia sustancial en lo dispositivo del fallo. 
Por estas consideraciones y visto, además, lo preceptuado en los artículos 500, 535, $541 \mathrm{~N}^{\circ}$ 9, $546 \mathrm{~N}^{\text {os }} 4^{\circ}$ y $7^{\circ}$ y 547 del Código de Procedimiento Penal, SE RECHAZAN el recurso de casación en el fondo promovido a fojas 3339 por la abogada doña Ema Salinas Fernández, en representación de los querellantes Carla Pellegrin Friedmann y Rafael Walker Salgado, y los recursos de casación en la forma y en el fondo deducidos por la Abogada Procurador Fiscal de Santiago, doña Lya Hald Ramírez, por el Consejo de Defensa del Estado, en lo principal y primer otrosí del libelo de fojas 3373, en contra de la sentencia de veintidós de julio de dos mil trece, que se lee a fojas 3308.

Se previene que el Ministro Sr. Juica, concurre al rechazo de la casación de fondo, solo compartiendo los fundamentos respecto de la falta de acreditación de la participación criminal de los acusados y para los efectos de lograr la mayoría legal requerida para la eficacia de esta sentencia, ya que en su concepto tiene una opinión diferente con respecto de que en la especie se halla configurada en grado de certeza la existencia de los homicidios calificados, según los hechos establecidos y que fueron fundamentados por los jueces de la instancia sobre la base de la prueba que la sentencia impugnada se encarga de señalar en sus respectivas motivaciones, para ello tiene presente las siguientes consideraciones:

1. Que la sentencia de primera instancia en su fundamentación cuarta asienta una conclusión básica, que los antecedentes probatorios aludidos en los considerandos anteriores no permiten dar por establecida la existencia de los delitos de homicidios investigados. Tiene dicho fallo presente, como primera consideración, que no se ha podido lograr la convicción que exige la norma del artículo 456 bis del Código de Procedimiento Penal, para estimar que realmente se ha cometido el ilícito imputado en esta causa. Agrega dicho fundamento que en el caso de los homicidios no basta que la muerte sea sospechosa o que algunos de los elementos de la causa apunten a la conclusión de que dicho suceso sea provocado, porque para ello se requiere un grado mayor de certeza, lo que implica una prueba seria y unánime, y que no haya contradicciones a su respecto, concluyendo que esa calidad de provocada de la muerte, ya sea en grado de natural o accidental, es la que tiene que ser probada. Se sostiene, luego, que para demostrar la existencia de los homicidios, el caso descansa en la prueba pericial, porque en la especie no hay otra prueba directa de esos ilícitos. Se explica que no existe testimonio alguno que refiera que se ejerció violencia contra Cecilia Magni y Raúl Pellegrin, o que se les haya arrojado al río o que se les introdujo a él una vez muertos o en estado de agonía. Se complementan las afirmaciones anteriores, con la convicción del sentenciador que no existen otros elementos ajenos a las pericias médicas que permitan presumir algunas de las hipótesis mencionadas o cualquiera otra que lleve a concluir que las muertes fueron provocadas por terceros.

2. Que frente a dicha limitación probatoria la sentencia se preocupa entonces de extraer antecedentes incriminatorios que pudieran emanar de las pericias médicas agregadas a los autos, partiendo en el motivo sexto con su desarrollo y concluyendo en un lato análisis lo más prolijo posible en el fundamento vigésimo séptimo, para extraer alguna conclusión positiva dentro de las múltiples contradicciones 
que presentan las autopsias efectuadas en autos y con las ratificaciones de los médicos respectivos con aquellas evacuadas por la Universidad de Chile y la que se refiere a la del perito Belletti, que no logran concluir definitivamente acerca de si la muerte de las víctimas se produjo por asfixia por inmersión o por aquellos traumatismos que se indicaron en la acusación judicial de oficio, de modo que ni el artículo 472 ni menos el 473, ambos del Código de Procedimiento Penal, sirven para llegar a una conclusión definitiva sobre tan trascendental hecho, de modo, que en dicha dinámica argumentativa es explicable la conclusión a que arriba el juez de primer grado, cuando en el motivo trigésimo expresa que luego de analizar exhaustivamente la prueba que se recogió en las diversas etapas de la causa, no es posible racionalmente y en un ejercicio imparcial y serio, concluir con la convicción de haberse cometido efectivamente los delitos de homicidios, lo que lo obliga finalmente a la decisión de absolución;

3. Que sin perjuicio de lo anterior, la sentencia de primera instancia, abunda a continuación, pese a que lo estima sobreabundante, a precisar en los considerandos siguientes los elementos de incriminación respecto de los acusados a fin de demostrar su participación ilícita en los hechos indagados, partiendo de la premisa que sobre este punto no existe prueba directa, no sólo de que algunos de los acusados provocara la muerte de los ofendidos, sino tampoco de que los hayan detenidos o tenidos alguna vez a su disposición, e incluso sobre la base de que en el operativo policial para detener a los hechores de un atentado a un retén policial, los funcionarios de carabineros también hubieren aprehendido a las víctimas que luego resultaron muertas, se llega igualmente al resultado de que no hay presunciones de que ese aserto haya sido efectivo, pero en todo caso, se afirma, esta última conclusión emanaría de una presunción basada en el supuesto de una cercanía temporal entre la huida de los guerrilleros y la llegada de la fuerza policial, lo que no constituye un elemento probatorio legalmente aceptable, ni tampoco pueda deducirse que luego fueron lanzados al río cuando se encontraban en estado agónico y sin posibilidad de sobrevivir en las aguas del mismo curso, analizando todas las posibilidades fácticas posibles y que se contienen en los motivos 36 a 39 de dicha sentencia;

4. Que aparte lo anterior, en segunda instancia los jueces de dicho grado tampoco satisfechos sobre el punto de demostración de un ilícito, vuelven a insistir en un nuevo peritaje encargado al doctor Javier Tapia Rojas del Servicio Médico Legal de Santiago, quien informa sobre todos aquellos puntos críticos referidos a la muerte de las víctimas el que es analizado en el considerando 18 de la sentencia de la Corte de Apelaciones, el que tampoco pudo llegar a una conclusión clara y definitiva sobre la verdadera causa de las muertes de Magni y Pellegrin, ya que concluye que existen elementos orientadores con el cuadro de asfixia por sumersión, tanto en el cuerpo de la primera, como en el del segundo y, a su vez, también hay elementos traumáticos en ambos cadáveres, cuyo origen tiene dos mecanismos posibles, tanto el arrastre a través de un lecho fluvial rocoso, como la acción de un elemento contundente aplicado por un tercero, dictamen que luego fue ratificado 
por el mismo perito ante el tribunal respectivo, aclarando que las fracturas que presentan los cadáveres pueden corresponder a una caída de Pellegrin, sin descartar que puedan deberse por golpes contra las rocas y con Magni también expresa que sus lesiones pueden corresponder a aquellas compatibles con el impacto de la piel con una estructura roma, las que pueden deberse al arrastre de las aguas, como a lesiones ocasionadas por terceros fuera del agua. El mismo perito advierte que con respecto a las lesiones anales sería conveniente practicar un estudio de histología, lo que se pudo hacer solo con respecto de la víctima Magni y cuya pericia determinó la existencia de una ampolla que puede ser sugerente de lesiones por electricidad de bajo voltaje, precisión que en todo caso no fue determinante para que los jueces de segunda instancia pudieran extraer de ese antecedente una presunción para determinar el delito de homicidio, con lo cual dicho fallo concuerda en su conclusión de absolución de que la prueba no resultó suficiente para una sentencia condenatoria, porque no aparecen presunciones que reúnan los requisitos del artículo 488 del Código de Procedimiento Penal para determinar la existencia del hecho punible, lo que es fundamental para sancionar penalmente a los acusados de autos;

5. Que como se sabe nuestro Código de Procedimiento Penal en la decisión de determinar un sistema racional de prueba, no optó por la fórmula de sistema de la certeza legal o verdad formal ni tampoco aquel método de entregar el establecimiento de los hechos a la libre conciencia o convicción del juez, escogiendo un término medio que corresponde al de la certeza legal condenatoria y moral absolutoria, como lo evidencia el mensaje de dicho cuerpo normativo en cuanto expresa: "De aquí que este proyecto consigna como una base general y superior a toda demostración jurídica, que la convicción del juez adquirida por los medios de prueba legal es de todo punto indispensable para condenar. Si esa convicción no llega a formarse, el juez podrá absolver sin otro fundamento y cualesquiera que sean los antecedentes que el proceso arroje en contra del reo". Sobre este punto la jurisprudencia ha sido constante, que el artículo 456 bis aludido no es una norma reguladora de la prueba ni contiene una disposición de carácter decisorio litis, sino que se limita a consignar una disposición encaminada a dirigir el criterio o conciencia del tribunal respecto al modo como debe adquirir la convicción de condena, agregando que en esta materia no es posible rever la apreciación de la fuerza de convicción que los jueces con sus facultades privativas atribuyen a las diversas probanzas que suministra el proceso (Repertorio de Legislación y Jurisprudencia Chilenas. Código de Procedimiento Penal, Editorial Jurídica de Chile, p. 124). De modo que la aludida norma solo debe entenderse con respecto al juez que sentencia, como un mandato que lo obliga a condenar sólo cuando se ha persuadido de la comisión de un hecho punible, convicción que solo es válida en la medida que haya sido adquirida por los medios de prueba legal. Este criterio no es del mismo modo aceptable para absolver porque en este caso la decisión es de carácter moral, permitiéndole la ley al juez la libertad para apreciar los antecedentes de la causa y decidir no sancionar cuando no se ha formado esa convicción de condena. 
Así lo ha sostenido un fallo de este Tribunal, declarando al respecto: "Conforme al espíritu de nuestra legislación, el estudio de la prueba en procesos criminales plantea para los jueces dos situaciones en orden a sus fallos, ya sea que se trate de absolver o de condenar a un inculpado. Los jueces tienen libertad para apreciar los antecedentes de la causa y fallar absolviendo a los inculpados cuando no se han formado convicción acerca de la existencia del delito o de la participación punible de aquéllos; pero no pueden proceder de igual modo cuando imponen condenas. En este último caso la libertad del juzgador queda restringida por la obligación que impone la ley de asentar el convencimiento en la demostración de que ese convencimiento se ha adquirido en virtud de que la existencia del hecho punible y la responsabilidad del reo se han establecido por medio de prueba legal. Para condenar, debe el juez basarse en que existen hechos punibles y responsabilidad criminal acreditados por medio de dicha prueba". (C. Suprema, 6 septiembre 1948. G., 1948, $2^{\circ}$ sem., No 54 , p. 323).

6. Que de este modo asentado por los jueces de la instancia, luego del examen de toda la prueba producida en la investigación de estos hechos punibles, su imposibilidad de haber adquirido la certeza legal exigida para condenar es evidente que se encontraban en la situación contraria, aceptada por la ley, de la certeza moral absolutoria, y descartada la existencia de un vicio de casación en la forma, en cuanto al contenido mismo de las sentencias analizadas, resulta necesaria examinar los libelos impugnatorios de dicha decisión. Al efecto, los recursos antes analizados se basan en la concurrencia de las causales de nulidad previstas en los $\mathrm{N}^{\text {os }} 4$ y 7 del artículo 546 del Código de Procedimiento Penal. La primera de ella permite la invalidación de la sentencia definitiva, en cuanto ésta ha calificado como lícito un hecho que la ley pena como delito y en tal virtud se absuelva al acusado. El segundo motivo es el quebrantamiento de las leyes reguladoras de la prueba y siempre que esta infracción influya sustancialmente en lo dispositivo del fallo impugnado. Desde luego, la primera cuestión de nulidad sustancial denunciada supone un error jurídico sobre la base de haber estimado la resolución recurrida configurado el hecho punible y, además, demostrada la participación punible de los acusados, estableciendo tal dictamen hechos configurativos de tales supuestos condenatorios y pese a ello se dicte una decisión de absolución, lo que no se produce en este caso, como se señaló en las motivaciones anteriores, en ambos extremos aludidos. Luego, para convenir con los recursos, necesariamente deberá acreditarse entonces la vulneración de las normas demostrativas de la evidencia, cuestión que el recurso propone sobre la base de un número importante de leyes que se pretenden reguladoras de la prueba. Estas, como se ha dicho por la doctrina y la jurisprudencia, son aquellas normas básicas que importan una limitación de las facultades privativas de los sentenciadores en la valoración de la prueba, y cuya infracción se produce, sustancialmente, cuando se invierte el peso de la prueba; cuando se rechaza un medio probatorio que la ley autoriza, o cuando se acepta uno que la ley repudia y cuando se altera el valor probatorio que el legislador da a los diversos medios de prueba. Esta limitante necesaria tiene su justificación precisamente, 
en cuanto a los límites a que se hallan sometidos los jueces, en este caso la Corte Suprema, precisamente para evitar que este tribunal se transforme en una tercera instancia, puesto que en materia de casación en el fondo le está vedado entrar a examinar, ponderar o aquilatar los medios probatorios mismos, ya justipreciados por los jueces del grado en el ejercicio de sus facultades soberanas, y a revisar las conclusiones a que éstos hayan llegado al respecto. (Jurisprudencia citada en el Repertorio antes indicado, pp. 276 y 278).

7. Que los dos recursos de casación en el fondo, con más o menos similares argumentos de convicción denuncian el quebrantamiento de los artículos 459, 472, 476, 478 y 488 N $^{\text {os }} 1,2$ y 4 del Código de Procedimiento Penal, atacando las declaraciones de los jueces de la instancia en cuanto a que no pudo establecerse que las víctimas fueran detenidas por funcionarios policiales, que procedieron a golpearlos, para luego ser arrojados al cauce del río Tinguiririca mientras agonizaban, con el objeto de hacer aparecer sus muertes como un accidente con motivo de la fuga de aquellas y que tampoco se pudo establecer la participación de terceros en las heridas que presentaban los cuerpos y tampoco pudo probarse, por los medios de prueba legales de la existencia de una detención previa. Agregándose que la sentencia expuso que no existen hechos probados o presunciones de tal entidad que permitan concluir que ambas víctimas, perseguidas por las fuerzas policiales en las cercanías del río donde fueron encontrados sus cuerpos, hayan sido previamente detenidas, golpeadas y arrojadas al cauce torrentoso. Con lo cual se sostiene se desecharon las presunciones que a partir de las resoluciones de procesamiento determinaban la existencia de los delitos de homicidio y que los peritajes, que se estiman contradictorios, cumplían con los requisitos previstos en los artículos 472 y 473 para darles el valor probatorio que acreditarían los delitos investigados. Se hace mucho causal en el recurso que en torno de las presunciones existían los hechos reales y probados, a partir de la existencia del atentado con resultado de muerte de un policía y la utilización de todos los medios policiales para detener a los hechores de dicho ataque y a la circunstancia de que las víctimas solo tuvieron media hora para escapar de las patrullas que las buscaban, aparte de las presunciones que pudieran emanar de los dichos de los detenidos Órdenes y Araya, todo lo cual, añade en cuanto a la autoría, el reconocimiento de los acusados de haber participado activamente en las diligencias policiales para la detención de los atacantes del retén de Los Queñes. En concreto los recursos, en torno a la infracción de las leyes reguladoras de la prueba discurren, sólo sobre un aspecto de la cuestión, esto es de la valoración ilegítima que en su entender dieron los sentenciadores a las indicadas normas probatorias. Con lo cual, el reclamo no mira a que los jueces hayan errado en torno a la carga de la prueba, ni que se haya rechazado un medio probatorio que la ley autoriza o haya admitido uno que la ley repudia y en este entendido, las normas invocadas, en su aspecto valorativo, en el presente caso, no son reguladoras de la prueba, puesto que, en primer lugar, siendo una sentencia absolutoria los jueces de la instancia estaban solo extremados a justificar por los medios de prueba legal el hecho punible y la participación culpable, pero ese 
rigor se mengua cuando se trata de la absolución, ya que, como se dijo, el artículo 456 bis citado exige una convicción mayor de certeza que de no lograrse le permite adoptar esa decisión de convicción moral absolutoria, cuestión privativa de los jueces del fondo y que por lo antes dicho le es prohibido a la Corte Suprema modificar o verificar la legitimidad de esa valoración;

8. Que aparte de lo dicho, las leyes probatorias denunciadas como quebrantadas no necesariamente en lo valorativo imponen un deber ineludible a los jueces del fondo de apreciarlas de una manera determinada e imperativa. Así el artículo 459 del código procesal indicado, dispone que la declaración de dos testigos hábiles, contestes en el hecho, lugar y tiempo en que acaeció, y no contradicha por otro u otros igualmente hábiles, en el supuesto que tengan estas calidades, lo que no se ha demostrado, solo otorga una facultad al tribunal, al utilizar la palabra "podrá" para estimar demostrado un hecho, con lo cual nada obliga en este punto al tribunal aparte de hacer las consideraciones pertinentes a su respecto. Lo mismo cabe decir con respecto al valor probatorio del informe pericial, ya que el artículo 472 emplea igualmente la expresión "podrá" para estimar si tiene el valor de prueba completa, pero además, se indica en la norma, que ese valor probatorio solo es posible si la pericia no se encuentra contradicha por la de otro u otros peritos, que es precisamente el problema de convicción que enfrentaron los jueces de la instancia frente a las claras contradicciones que presentaban los innumerable peritajes encargados en torno a los hechos incriminados. Que permite una valoración distinta como le asigna el artículo 473, en cuanto la libertad que se le entrega al tribunal en su apreciación como una presunción judicial si el peritaje no cumple los requisitos de la norma anterior. En cuanto a la infracción del artículo 476 del mismo Código, que se refiere a la prueba inspección personal del tribunal, la verdad que ese precepto contiene una norma imperativa pero acotada a una diligencia del tribunal en que se hicieren constar las observaciones que el juez haya hecho por sí mismo con asistencia del secretario, en los lugares que hubiere visitado con motivo del suceso, o los hechos que hubieren pasado ante uno y otro funcionario. Esta diligencia está referida al acta de constitución del tribunal en Hueñi y que rola a fs. 1050, que confirmarían ciertas hipótesis en cuanto a la probable dirección que debieron tomar los fugitivos en su huida para evitar la detención por las fuerzas policiales, pero la verdad es que dicha diligencia practicada varios años después de los hechos investigados deja constancia de situaciones probables de movimientos de las víctimas y de la manera como habrían sido perseguidas por la policía, por lo que en el terreno de las probabilidades no es posible asegurar la existencia de un hecho demostrativo de un delito y de participación, de modo que como lo hace la sentencia impugnada tampoco en su defecto podría alcanzar el mérito de una presunción judicial. Que en lo que respecta a la infracción al artículo 478 del Código aludido, su quebrantamiento se denuncia con respecto a la actividad de los hechores, la que de ser efectiva, lo que no está demostrado, está referida a la participación criminal imputada a los acusados, que pierde trascendencia si se ha concluido que no está demostrado el hecho punible. En fin la 
vulneración a los $\mathrm{N}^{\mathrm{os}} 1,2$ y 4 del artículo 488 del mismo Código, no pueden ser atendidas ya que su incidencia como norma reguladora de la prueba pierde consistencia aunque pudieran existir algunos indicios que le den un cierto carácter sospechoso a la muerte de las víctimas, pero que no es suficiente para contradecir el valor mayor de convicción que exige el artículo 456 bis del Código de Procedimiento Penal;

9. Que de este modo, convencido el previniente, de la inexistencia de vulneración de las leyes reguladoras de la prueba, quedan vigentes los hechos establecidos por los jueces de la instancia en cuanto no estiman demostrados los supuestos básicos del homicidio de las víctimas ni una participación punible, es obvio suponer que tampoco concurren las infracciones a las leyes de fondo que se han denunciado para justificar la causal de nulidad prevista en el $\mathrm{N}^{0} 4$ del artículo 546 del Código antes citado.

Acordada con el voto en contra de los Ministros Sres. Dolmestch y Escobar quienes fueron de opinión de acoger el recurso de casación en el fondo deducido por la querellante, invalidando la sentencia de alzada a fin de dictar la correspondiente de reemplazo que haga efectiva la responsabilidad penal de los acusados de autos en los hechos que se han dado por acreditados.

Para ello tuvieron en consideración los siguientes antecedentes:

1. Que las reparticiones de la policía uniformada en la persecución terrorista a consecuencia del atentado a Los Queñes procedieron en conformidad al denominado Plan Lince, cuyo objetivo era evitar y repeler atentados terroristas.

2. El mando y control del operativo a cargo de la detección, neutralización y captura del grupo terrorista que atentó contra el poblado y Retén Policial de Los Queñes, en octubre de 1998, fue ejecutado por el prefecto de la Prefectura de Colchagua coronel Walter Soto Medina.

3. Que la coordinación en terreno de las diferentes unidades de Carabineros que tuvieron participación directa en el operativo la ejecutó, desde el 25 de octubre de 1988, el subprefecto de los Servicios de la Prefectura de Colchagua, teniente coronel Julio Acosta Chávez.

4. Que Julio Acosta Chávez reconoce que Walter Soto Medina asumió el mando general del operativo policial y que dispuso que la Primera Comisaría de San Fernando sería la unidad base de las operaciones policiales. También declara que los prófugos que fueron detenidos los días 25 y 26 de octubre de 1988 aportaron antecedentes sobre el escondite de Cecilia Magni y Raúl Pellegrin, y reconoce que participó en operativos en la comunidad Hueñi, lugar al que llegó veinte minutos después de la huida de Magni y Pellegrin, lugar donde estaba Rivera Irachet, quien habría informado la realización de un rastreo en los alrededores sin resultados. Sin embargo, en una nueva búsqueda, Julio Acosta reconoce que se encontraron especies de los prófugos. 
5. Que el teniente Carlos Bezmalinovich Hidalgo, Jefe de la Patrulla del Gope que arribó al lugar, mantuvo vigilancia de la comunidad Hueñi la noche del 27 de octubre de 1988 y siguientes.

6. Que como se acreditó pericialmente en la causa, es conveniente destacar que el Gope es una unidad especializada de comandos, en que la formación de sus integrantes incluye artes marciales y defensa personal, actividades antiguerrilla, buceo táctico policial, montañismo y rescate, manejo de armamento de precisión y alto poder, entre otras. El acusado Bezmalinovich declaró haber participado en el operativo a la comunidad Hueñi del día 27 de octubre de 1988, día que ha sido fijado como el de la muerte de las víctimas.

7. Sea que la muerte se haya ejecutado por un grupo de carabineros que actuó en forma autónoma, sin que el mando tomara conocimiento de los hechos, o bien se ejecutara por un grupo de Carabineros en forma autónoma debiendo el mando operativo encubrir los hechos, lo cierto es que todas las pruebas sitúan a los acusados en el lugar en los momentos inmediatos al que fueron vistas por última vez con vida.

8. Que es un hecho de la causa que las víctimas eran objeto de una gran persecución policial y que el cerco que los rodeaba, gestado por los antes mencionados, fue totalmente efectivo, encontrándose los cuerpos sin vida de estas víctimas al interior de ese radio de acción. Tal es así, que resultó demostrado que las vías principales de escape habían sido bloqueadas por el contingente policial que hizo uso de todos los medios materiales y humanos de que pudo disponerse, operativo que en pocos días logró la detención de la mayoría de los prófugos, pretendiendo la defensa que en este caso ni siquiera dieron con los cuerpos mortales de Magni y Pellegrin, los que fueron avistados por un lugareño, como revela el proceso.

9. Esa efectividad de la acción de los captores evidencia de forma suficiente que los prófugos Magni y Pellegrin no pudieron huir, siendo aprehendidos, circunstancias en las que se les torturó, provocándoles las lesiones mortales de que dan cuenta las pericias de autos.

10. Que los antecedentes que preceden constituyen presunciones suficientes para dar por establecida la participación de los encausados en calidad de autores de los homicidios de Raúl Pellegrin Friedmann y Cecilia Magni Camino, cometido en el sector precordillerano de la Sexta Región entre el 27 y 29 de octubre de 1988, delitos por los que debieron ser condenados.

11. Que, asimismo, estuvieron por revocar la sentencia de primer grado en cuando denegó la acción civil deducida en contra del Fisco de Chile y, desechando las excepciones opuestas por éste, fueron del parecer de acoger la demanda deducida por los actores.

Regístrese y devuélvase con sus agregados.

Redacción a cargo del Ministro Sr. Cisternas y de la prevención y del voto en contra, sus autores.

Rol No 6373-13. 
Pronunciado por la Segunda Sala integrada por los Ministros Sres. Milton Juica A., Hugo Dolmestch U., Guillermo Silva G., Lamberto Cisternas R. y Juan Escobar Z. No firman los Ministros Sres. Juica y Silva, no obstante haber estado en la vista de la causa y acuerdo del fallo, por estar en comisión de servicios y con feriado legal, respectivamente.

Autorizada por la Ministro de Fe de esta Corte Suprema.

\section{Comentario}

\section{Procesos penales y justicia de transición}

En la historia de los esfuerzos desplegados para hacer frente a un pasado de violaciones graves de derechos humanos, por las diversas comunidades políticas que han transitado hacia su reconstitución tras dictaduras o conflictos armados, el recurso al derecho penal y al proceso judicial ha tenido y sigue teniendo un papel protagónico. Un papel central que el derecho internacional ha tendido también a consolidar, tanto a través del progresivo fortalecimiento jurisprudencial, en los sistemas regionales de protección de derechos humanos, de los deberes estatales de investigación y persecución, como a través de la configuración de una jurisdicción penal internacional para delitos de lesa humanidad.

La experiencia chilena desde el retorno a la democracia ilustra también ese rol, en algún sentido imprescindible, que los procesos judiciales tienden a jugar en la justicia de transición. Tras una primera etapa, marcada por la barrera que significó inicialmente el decreto ley de amnistía de 1980 y por la opción política de constituir una Comisión Nacional de Verdad y Reconciliación que investigara los hechos más graves, la vía judicial fue afianzándose a partir de 1998 como la forma definitiva de abordar públicamente el problema del terror estatal durante la dictadura ${ }^{2}$.

Diversas razones suelen ser mencionadas cuando se trata de justificar el aporte distintivo de los procesos penales a la justicia de transición. Para efectos de este comentario, interesa observar que ellas no sólo apuntan a la relevancia de la exclusión de la impunidad, a través de la sanción de quienes participaron en los actos de violencia estatal, como garantía de su no repetición en el futuro, sino también a la contribución propia de los procesos judiciales a la determinación de la verdad acerca de lo ocurrido y a la deliberación pública en torno a ella ${ }^{3}$. El establecimiento judicial de los hechos representaría,

${ }^{2}$ Cfr. sobre esta evolución, entre otros, Hunneus, A., "Judging from a guilty conscience: the chilean judiciary human right turn”, en Law and society inquiry, Vol. 35, N 1, pp. 99-135 y Collins, C. "La política de la justicia: Chile más allá del caso Pinocher”, en Collins, C., Hite, K. y Joignante, A. (eds.), Las políticas de la memoria en Chile: desde Pinochet a Bachelet, Santiago, Ediciones Universidad Diego Portales, 2013, pp. 85-115.

${ }^{3}$ Esta conexión entre procesos judiciales y verdad no solo ha sido sostenida por la literatura sobre justicia transicional (vid. nota siguiente), sino que, por una parte es asumida frecuentemente en el discurso de los propios operadores (vid. Accatino, D. y Collins, C., "Truth, Evidence, truth: the deployment of testimony, archives and technical data in domestic human rights trials", en Journal of Human Rights Practice, 2016, pp. 1-20) y, por otra ha sido articulada normativamente en la jurisprudencia de los órganos del sistema 
desde esta perspectiva, una forma privilegiada de reconstrucción pública u oficial de la verdad, que se distinguiría de otras, como las que son propias de las comisiones de verdad, por su imparcialidad -al ser asumida por un poder cuyo diseño institucional apunta, precisamente, a la cautela de su independencia, mediante un procedimiento que considera la participación no solo de las víctimas o de quienes las representan, sino también de los acusados- y por su rigor -al fundarse en pruebas sometidas a la contradicción de las partes y al escrutinio público. La forma judicial de investigación y fijación de los hechos estaría dotada, de este modo, de una especial autoridad y publicidad, que favorecería su reconocimiento o aceptación y la formación de una memoria colectiva en torno a las pasadas políticas de terror ${ }^{4}$.

Esta aproximación a los procesos judiciales como un mecanismo privilegiado de reconstrucción de la verdad en contextos de transición se enfrenta, sin embargo, a algunas dificultades que resultan bien ilustradas en las sentencias dictadas en los procesos por las muertes, en 1988, de Cecilia Magni y Raúl Pellegrin. En particular, me interesa poner de relieve que no se suele advertir que la labor del juez en la reconstrucción de los hechos del caso está sujeta a numerosos límites institucionales, impuestos por las normas procesales y probatorias, que pueden estar orientadas a cautelar fines o valores diversos a la averiguación de la verdad. Así ocurre con las normas que excluyen que ciertas informaciones puedan presentarse como pruebas o ciertas personas deban declarar como testigos, a pesar de que podrían aportar al esclarecimiento de los hechos, porque han sido ilícitamente obtenidas, por ejemplo, en el primer caso, o porque se trata de cautelar vínculos familiares o de confianza, en el segundo. Es lo que pasa también -como lo muestran las sentencias en el caso que es objeto de este comentario- con las reglas que en el proceso penal fijan estándares de prueba muy altos para la condena, con el fin de evitar especialmente el riesgo de error al atribuir responsabilidad penal, aun a costa

interamericano de protección de los derechos humanos. Así, se considera que un componente del derecho a la protección judicial y a las garantías procesales, reconocidos por la Declaración y la Convención Americana, consiste precisamente en "el derecho de las víctimas y sus familiares a conocer la verdad de los hechos que dieron lugar a graves violaciones de derechos humanos, así como el derecho a conocer la identidad de quienes participaron en ellos' y que este derecho supone 'la obligación de los Estados de esclarecer, investigar, juzgar y sancionar a las personas responsables de graves violaciones de derechos humanos' (Cfr. Comisión Interamericana de Derechos Humanos, 2014:33). Por otro lado, se afirma que la dimensión colectiva del derecho a la verdad requiere tanto el inicio de oficio - no condicionado, por tanto a la existencia de demandas iniciadas por las víctimas- de las investigaciones como la divulgación pública de los procesos penales e investigativos. Además, en varias sentencias, la Corte Interamericana ha dicho que “(...) la dimensión colectiva del derecho a la verdad exige la determinación procesal de la más completa verdad histórica posible, lo cual incluye la determinación judicial de los patrones de actuación conjunta y de todas las personas que de diversas formas participaron en dichas violaciones y sus correspondientes responsabilidades" (cfr. Ibíd., 38). Sobre este desarrollo jurisprudencial, cfr., Méndez, J. E., "The human right to truth: lessons learned from latin American experiences with truth telling”, en Borer, T. A. (ed.), Telling the truths: truth telling and peace building in post conflict societies, University of Notredame Press, Notredame, 2006.

${ }^{4}$ Cfr., entre la literatura acerca de esta función de los procesos en contextos de justicia de transición, Nino, C.S., Juicio al mal absoluto, Ariel, Buenos Aires, 1996; Osiel, M., Mass atrocity, collective memory and the law, Transaction Publishers, New Brunswick, NJ, 1997; Almqvist, J. y Espósito, C. (eds.), The role of courts in transitional justice, Routledge, Londres, 2012. 
de tener que aceptar que aumente el riesgo de error al absolver (asumiendo que, como rezan las fórmulas clásicas, es preferible diez, cien o hasta mil culpables sean absueltos a que un solo inocente sea condenado injustamente $)^{5}$.

En las causas por violaciones de derechos humanos la aplicación de estas reglas probatorias puede dar lugar a que las informaciones o evidencias sobre la base de las cuales una cierta reconstrucción de los hechos ha sido aceptada como verdadera en investigaciones históricas que se han hecho públicas o, más significativamente aún, en los informes de la Comisión de Verdad y Reconciliación (Informe Rettig) o de la Comisión sobre Prisión Política y Tortura (Informe Valech), no sean admitidas como pruebas o bien sean consideradas insuficientes para tener por probados esos mismos hechos en sede judicial. Esto último es precisamente lo que ocurrió con las decisiones de primera y segunda instancia en la causa Magni y Pellegrin. El particular dilema al que este posible contraste -entre las "verdades judiciales" y las verdades históricas (aceptadas a la luz de ciertas informaciones en diversos contextos) o las verdades reconocidas institucionalmente por las comisiones de verdad- enfrenta a los jueces que instruyen los procesos por crímenes atribuidos al terror estatal, se refleja muy bien en algunos fragmentos de la sentencia de segunda instancia que se reseñarán y en la pluralidad de votos de la sentencia de la Corte Suprema que es objeto de este comentario.

\section{La reconstrucción de la historia de la muerte de Cecilia Magni y Raúl Pellegrin}

Cecilia Magni y Raúl Pellegrin eran dos figuras emblemáticas del Frente Patriótico Manuel Rodríguez que participaron en el asalto al retén de carabineros de Los Queñes, donde resultó muerto el cabo Juvenal Vargas Sepúlveda. El FPMR había defendido la estrategia de la "rebelión popular" frente a la dictadura y la reafirmó mediante esa acción en los días posteriores al plebiscito de 1988.

Tras el asalto, el comando se dividió en grupos que huyeron a refugiarse hacia distintos puntos de la cordillera. Un intenso operativo policial se desplegó en la zona y varios frentistas fueron detenidos en los días siguientes. Algunos días después, Magni y Pellegrin fueron encontrados muertos en el Río Tinguiririca.

La versión oficial de la época señalaba que habrían muerto ahogados al intentar cruzar el río Tinguiririca para eludir el cerco policial. Esa versión fue descartada por las familias de las víctimas, a partir de las lesiones que observaron al recibir sus cuerpos y que describen sus autopsias y de otras informaciones sobre las circunstancias en que se habría producido su muerte.

Esos antecedentes fueron aportados a la Comisión Nacional de Verdad y Reconciliación, que se pronunció sobre el caso en su Informe (Volumen I, Tomo II, p. 1009) en los siguientes términos:

${ }^{5}$ Las fórmulas reseñadas corresponden a, respectivamente, Blackstone en el siglo XVIII, Benjamin Franklin en el mismo siglo y Moisés Maimónides en el siglo XII. Sobre esta función del estándar de prueba penal, cfr. Accatino, D., "Certezas, dudas y propuestas en torno al estándar de prueba penal", en Revista de Derecho (Valparaíso), No 37, 2011, pp. 483-511. 
"El 21 de octubre de 1988 un grupo del FPMR a cargo de los máximos dirigentes Cecilia MAGNI CAMINO y Raúl PELLEGRIN FRIEDMANN, atacó el poblado de Los Queñes donde muere un cabo de Carabineros; hecho esto, emprendió su huida por las montañas.

Días más tarde, el 28 de octubre de 1988, en el río Tinguiririca fue encontrado el cadáver de Cecilia Magni y el 31 de octubre lo sería el de Raúl Pellegrin.

Según los informes de autopsia ambos cadáveres presentan lesiones contusas y huellas de aplicación de electricidad.

En cuanto al cadáver de Raúl Pellegrin se señala que la causa de muerte fue asfixia por sumersión en el agua y contusiones torácicas dorsales, las que se aplican por acción de instrumentos romos contundentes, dada su topografía y profundidad y la ausencia de lesiones externas.

La Comisión, evaluando toda la información recibida, ha llegado a la convicción de que Cecilia Magni y Raúl Pellegrin, en su huida fueron detenidos, torturados y ejecutados por agentes del Estado, por lo que considera sus muertes violaciones a los derechos humanos de responsabilidad de dichos agentes".

El proceso penal que se inició cuando se encontraron los cuerpos de Magni y Pellegrin, concluyó -tras numerosos giros, largas pausas y reaperturas- en primera instancia con una sentencia que no consideró probada la existencia de los homicidios y absolvió a los acusados ${ }^{6}$. Esta determinación de los hechos generó intensa discusión en segunda instancia y ante la Corte Suprema. Reseñaré brevemente los desplazamientos que se observan con respecto a las pruebas que se estiman relevantes y la valoración de su fuerza probatoria en las diversas sentencias, para concluir con algunos comentarios acerca de la sentencia de la Corte Suprema.

La sentencia de PRIMERA INSTANCIA (que puede consultarse en http://www.elmostrador.cl/media/2010/10/PELLEGRIN-Y-MAGNI.pdf) asume, respecto de las pruebas relevantes, que "para demostrar en este juicio la existencia de los dos homicidios, todo el caso descansa en los peritajes porque en la especie no bay ninguna otra prueba directa de aquellos; es decir, no existe testimonio alguno que refiera que se ejerció violencia contra Cecilia Magni y Raúl Pellegrin, que se les arrojó al río o que se les introdujo a él una vez muertos o en estado de agonía. No hay tampoco otros elementos ajenos a las pericias médicas que permitan presumir algunas de las hipótesis mencionadas o cualquier otra que lleve a concluir que las muertes fueron provocadas" (Cons. $5^{\circ}$, cursivas agregadas).

Esas pericias son, básicamente, los informes de las autopsias, más diversos informes que interpretan las lesiones que se constatan en ellos ${ }^{7}$. El juez considera que los

\footnotetext{
${ }^{6}$ Los acusados eran: el Prefecto de Colchagua, coronel Walter Soto Medina, bajo cuyo mando y control se realizó el operativo policial; el subprefecto de Servicios de la misma prefectura, teniente coronel Julio Acosta Chávez, a cargo de la coordinación en terreno; el comisario de San Fernando, Juan Ernesto Rivera Iratech y el teniente Carlos Bezmalinovic Hidalgo, jefe de la patrulla del GOPE que participó en el operativo.

${ }^{7}$ Los que, como dice el tribunal, "en rigor, (...) son peritajes sobre peritajes" (Cons. 6 ${ }^{\text {; }}$ incluso, algunos de ellos, peritajes sobre peritajes de peritajes). El principal peritaje considerado como prueba de cargo fue
} 
peritajes que se invocan como prueba de cargo merecen "reparos que a la luz de la simple lógica puede formular cualquier lego en medicina" y resultan "contradichos en forma rotunda" por el dictamen de otro perito (Cons. $14^{\circ}$ ). Tras dar cuenta de esos reparos y contradicciones, basados "la lógica o los conocimientos elementales de medicina legal que pertenecen al abogado", el magistrado concluye que cuanto menos han generado un seria duda "que a todo evento impide que el Tribunal se forme la convicción de que han ocurrido los homicidios"8.

Descartada la prueba de los homicidios la sentencia argumenta que en todo caso, aún si se hubieran tenido por acreditados, no había en el expediente pruebas suficientes de la participación de los acusados. Sostiene el juez que toda la incriminación se basa en la hipótesis de la detención, respecto de la cual no es prueba directa. No hay tampoco presunciones de la detención, pero aunque hubiera presunciones ellas no podrían justificar la condena, pues se trataría de "presunciones basadas en otra presunciones", algo expresamente excluido por el artículo 488 numeral $1^{\circ}$ del Código de Procedimiento Penal (en adelante CPP).

La sentencia de SEGUNDA INSTANCIA (disponible en http://www.elrancahuaso. cl/sites/elrancahuaso.cl/files/pellegrin_y_magni_rancagua.pdf) concentra su argumentación en el análisis de dos nuevos peritajes cuya práctica se decreta como medida para mejor resolver. Las dos pericias son muy interesantes. La primera es un nuevo informe pericial que analiza los protocolos de autopsia, realizado por un perito médico tanatólogo del Servicio Médico Legal de Santiago, al que se le pide que se pronuncie sobre la fecha y causa de muerte y sobre "las aparentes contradicciones de las pericias anteriormente efectuadas con relación a las heridas que presentaban los cuerpos debido al arrastre de las aguas o si aquellas fueron causadas por terceros". La reseña que la sentencia de la Corte de Apelaciones de Rancagua hace del informe comienza por advertir que la muerte por asfixia por sumersión corresponde "a un campo aún complejo para la medicina forense, entre otras causas, porque no existe algún patrón de hallazgo único, tampoco existen a la fecha exámenes de laboratorio complementarios inequívocos” y "(m)uchas veces los hallazgos señalados históricamente por la literatura (...) tienden a entrelazarse con aquellos signos propios de la permanencia de un cadáver en el agua" (Cons.18 ${ }^{\circ}$ ). Respecto del caso en cuestión se reseña que el informe concluye que "que existen elementos orientadores con el cuadro de asfixia por sumersión, tanto en el cuerpo de Cecilia Magni Camino, como en el de Raúl Pellegrin Friedmann, a su vez, también hay elementos traumáticos en ambos cadáveres, cuyo origen tiene dos mecanismos posibles, tanto el arrastre a

realizado por el Departamento de Medicina Legal de la Universidad de Chile, el contradictorio fue realizado, no se sabe si habiéndolo decretado el juez de oficio o a petición de parte, por un perito en patología forense y anatomía patológica de la Brigada de Homicidios de la Policía de Investigaciones.

${ }^{8}$ Faltando esa certeza, lo que hay, sostiene el juez, son preguntas o dudas que la hipótesis de la muerte accidental no responde, aunque la avalen diversas "pistas”. Pero esas dudas respecto de la hipótesis, a juicio del juez, más probable, "no pueden llevar a formar la convicción necesaria para dictar condena" (Cons. 28 $)$, dado que, afirmaba antes, "la idea primera que nunca cabe olvidar al fallar este tipo de causas" es que "no es la atipicidad de la muerte, sino precisamente su adecuación al tipo de homicidio lo que cabe probar". 
través de un lecho fluvial rocoso, como la acción de un elemento contundente aplicado por un tercero" (Cons. $18^{\circ}$ ).

La segunda de las pericias consiste en un examen histológico de la muestra correspondiente a Cecilia Magni (la de Raúl Pellegrin no fue encontrada en los archivos del Servicio Médico Legal) a fin de establecer, especialmente, el origen de las laceraciones descritas en la región anal. Confirmando la tesis sostenida por otras pericias, el informe concluye, según reseña la sentencia, que "aun cuando la erosión de la piel anal no es característica, la lesión ampollar de la vecindad es altamente sugerente de haber sido producida por calor, como se describe en la periferia de lesiones por electricidad de bajo voltaje y que las lesiones anales son previas a la muerte, más de 24 horas aproximadamente" (Cons. $18^{\circ}$ ) .

Las dos nuevas pericias no resultan suficientes a juicio de la Corte de Apelaciones, tampoco, para "extraer (...) la certeza de que las muertes de Cecilia Magni y Raúl Pellegrin fueron consecuencia de la acción de terceros, sino solo la posibilidad alternativa a una caída accidental a las torrentosas aguas del río que son capaces de producir las lesiones encontradas en ambos cuerpos" (Cons. 21 $1^{\circ}$. Sin embargo, es interesante observar que la sentencia de segunda instancia atribuye al menos relevancia a otros datos probatorios -referidos a la intensidad del cerco policial y a las circunstancias en que se habría producido la huida- aunque considera que su fuerza no es suficiente para fundar presunciones que cumplan los requisitos que el artículo 488 del CPP establece para que cuenten como plena prueba, de modo que la hipótesis de la detención de Magni y Pellegrin "no pasa más allá precisamente de eso, una hipótesis, y no se puede condenar con ese estándar de prueba” (Cons. $21^{\circ}$ ).

Aunque la sentencia confirma la decisión de primera instancia, se formulan en ella algunas declaraciones, inusuales en las sentencias penales ordinarias, que dan cuenta de la incomodidad que parece producir, en esta clase de procesos, el no poder confirmar ni descartar con certeza la hipótesis de la muerte de las víctimas a manos de agentes del Estado. Así, afirma que "se hicieron denodados esfuerzos por parte de los jueces a cargo de la investigación" para acreditar esa "posibilidad alternativa" y, luego, que en definitiva "(l) a hipótesis planteada por la parte querellante se sostiene en un hecho que no pudo ser probado, a pesar de los años de investigación, donde se puede afirmar claramente que se bizo todo lo posible para agotar todas las instancias, reabriéndose la investigación cuando se estimó necesario, decretándose medidas para mejor resolver en segunda instancia” (Cons $21^{\circ}$ ).

La sentencia de la CORTE SUPREMA, en un fallo dramáticamente divido, con dos opiniones disidentes, una de ellas sostenida por dos votos, confirma la decisión de absolución y rechaza el recurso de casación en el fondo, pero declara que la sentencia de segunda instancia incurrió en un error en el establecimiento de los hechos al no tener por probada la existencia de los delitos de homicidio. Aunque se trata de un error que carece en definitiva de influencia en la parte dispositiva del fallo, pues el voto mayoritario estima que no puede tenerse por probada la participación de los acusados, se declara y justifica en la sentencia que la Corte de Apelaciones habría errado al desestimar la hipótesis del homicidio "por carecer de elementos para preferir una tesis sobre otra" (Cons. $9^{\circ}$ ). A juicio de la opinión de mayoría (a la que se suma en este punto la opinión de los 
dos votos que sostienen una de las opiniones disidentes) la intervención de terceros en la muerte de Magni y Pellegrin es la única hipótesis que explica tanto algunas coincidencias relevantes entre los informes periciales - la existencia de un patrón de lesiones similar, que pudieron contribuir causalmente a la muerte, algunas de las cuales solo pudieron ser provocadas mientras las víctimas permanecían desnudas- como la aparición de los cuerpos en el río Tinguiririca dada la ruta de huida acreditada (por la ubicación de los efectos personales que dejaron al huir y por la inspección personal del Ministro en visita), que se habría realizado por una huella que se interna hacia el suroeste, alejándose del río, de manera que para alcanzarlo las víctimas habrían tenido que devolverse tomando la ruta por la que se acercaban las fuerzas especiales. A juicio de la opinión de mayoría, "esta multiplicidad de hechos, reales y probados, permiten establecer presunciones de tal entidad que llevan inequívocamente a concluir que ambas víctimas, perseguidas por las fuerzas policiales en las cercanías del río donde fueron encontrados sus cuerpos, fueron detenidas, golpeadas y arrojadas al cauce torrentoso moribundas, con lo que el desenlace conocido era inevitable" (Cons. $15^{\circ}$ ).

Aun debiendo tenerse, de este modo, por probada la existencia de los homicidios, la decisión de mayoría confirma la falta de prueba de la acusación, dado que para emitir un fallo condenatorio "no basta con adherirse a una teoría o hipótesis de cómo sucedieron los hechos”. Aunque se asuma como probado el hecho de la detención, dado que no existen pruebas referidas a las circunstancias en que ella se produjo, no es posible atribuir, en forma individualizada, participación a los acusados en la muerte de las víctimas. Su participación -señala la sentencia retomando una fórmula que utilizaba también la sentencia de primera instancia- sólo podría presumirse sobre la base, a su vez, de una presunción sobre el lugar y las circunstancia en que se produjo la detención, presunción basada en presunción que es excluida por las reglas de prueba del artículo 488 del CPP.

El contrapunto de la opinión de mayoría con las dos prevenciones que se agregan a la sentencia pone de relieve la necesidad de una elaboración más detenida de las reglas acerca de la suficiencia de la prueba aplicables a esta clase de casos. Así, la prevención del Ministro Juica lleva a preguntarse cómo puede configurarse un error al no tener por probado un hecho dada la interpretación usual del artículo 456 bis CPP como una autorización al juez a fallar conforme a su convicción personal, que le permite no tener por probado un hecho en que se funda la acusación si no se encuentra personalmente persuadido de su ocurrencia. Parece prometedora la idea, tácitamente asumida en la opinión de mayoría, de un estándar de prueba articulado en términos que no remitan a la pura convicción subjetiva del juzgador y que fije las condiciones bajo las cuales debiera aceptarse una hipótesis en atención a su capacidad explicativa respecto de los datos probatorios, aunque concurra con otras hipótesis explicativas, dado que las certezas absolutas no son posibles en el ámbito probatorio. Su elaboración más precisa y la justificación de su aplicación diferenciada a distintos hechos a probar -la existencia de homicidios y la participación- es el desafío que plantea la prevención de los Ministros Dolmestch y Escobar, que estiman que dado que se tuvieron por probados los homicidios debió tenerse por probada también la participación de los acusados, sugiriendo que la 
sola alusión a la fórmula de la exclusión de presunciones basadas en presunciones no resulta suficientemente precisa.

Aunque falta en la sentencia una elaboración detenida de estas cuestiones, la intuición que la opinión de mayoría expresa en el sentido de que deba evaluarse diferenciadamente la suficiencia de la prueba para tener por probada la existencia de ciertos de los delitos investigados y para dar por acreditada la participación, puede ofrecer un espacio para enfrentar las complejas expectativas que recaen sobre los procesos judiciales en contextos de transición política. Esa diferenciación podría permitir conciliar, en casos de muy compleja prueba, la expectativa de que los procesos contribuyan a la construcción de un relato común acerca del pasado de terror estatal, dialogando con las instancias previas de configuración de esa historia, y la expectativa de que pongan fin a la impunidad a través de juicios justos, en los que la responsabilidad de los acusados sea establecida conforme a derecho y mediante la evaluación rigurosa de pruebas, evitando el riesgo de ser percibidos como instancias de venganza o de castigo a chivos expiatorios y confirmando de ese modo la diferencia entre el nuevo régimen y la violencia del régimen dictatorial que se juzga. 